\title{
A CLINICAL STUDY OF PATTERN OF SKIN MANIFESTATIONS IN PATIENTS WITH SYSTEMIC LUPUS ERYTHEMATOSUS ATTENDING DERMATOLOGY OPD IN A TERTIARY CARE CENTRE
}

\author{
Bhaskar Gupta1, Adhyatm Bhandari², Mahimanjan Saha3 ${ }^{3}$ Vaswatee Madhab ${ }^{4}$
}

${ }_{1}^{1}$ Professor and HOD, Department of Dermatology, Silchar Medical College, Silchar, Assam, India.

2 Post Graduate Resident, Department of Dermatology, Silchar Medical College, Silchar, Assam, India.

${ }^{3}$ Post Graduate Resident, Department of Dermatology, Silchar Medical College, Silchar, Assam, India.

${ }^{4}$ Post Graduate Resident, Department of Dermatology, Silchar Medical College, Silchar, Assam, India.

\begin{tabular}{l} 
ABSTRACT \\
\hline BACKGROUND \\
Systemic Lupus Erythematosus (SLE) is an autoimmune connective tissue disease with multi-organ involvement with skin being \\
the second most commonly affected organ. SLE with skin lesions can produce considerable morbidity resulting from painful skin \\
lesions, oral ulcers, disfigurement or toxic epidermal necrolysis like manifestations, etc. Skin lesions in patients with lupus may be \\
specific (LE specific) or non-specific (LE non-specific) as per the Gilliam classification of skin lesion associated with Lupus \\
Erythematosus (LE). Patients with acute cutaneous LE (Lupus specific) have high chances of having systemic disease.
\end{tabular}

\section{OBJECTIVE}

To see most common cutaneous manifestations of Systemic Lupus Erythematosus (SLE) in patients of North-East India.

\section{METHODS}

It was a case-series collected from Department of Dermatology, Silchar Medical College, Silchar, Assam. Total 38 patients with SLE fulfilling the clinical and laboratory criteria of the American Rheumatology Association (Updated 1997) were examined and followed-up for cutaneous manifestations between April 2013 and March 2016.

\section{RESULTS}

The mean age of patients was 26 years; $92 \%$ patients were female and $8 \%$ were male. Out of 38 patients, oral ulcers were seen in $26(68.42 \%)$, malar rash in 21 (55.26\%), photosensitivity in 21 (55.26\%) patients, discoid rash in 14 (36.84\%), alopecia in 20 (52.63\%), palpable purpura in 10 (26.31\%), nail changes in 10 (26.31\%), erythema multiforme in 7 (18.42\%), Raynaud's phenomenon in $5(13.15 \%)$, subacute cutaneous LE in $3(07.89 \%)$, bullous eruptions in $3(07.89 \%)$, telangiectasia in $2(05.26 \%)$, facial oedema in $2(05.26 \%)$, lupus panniculitis in $1(02.63 \%)$, cheilitis in $1(02.63 \%)$, lichen planus in $1(02.63 \%)$.

\section{CONCLUSION}

SLE is predominantly seen among young female patients. Oral ulcer was the most common manifestation followed by malar rash and photosensitivity in our study.

\section{KEYWORDS}

Systemic Lupus Erythematosus, Cutaneous Manifestations, Oral Ulcers, Malar Rash.

HOW TO CITE THIS ARTICLE: Gupta B, Bhandari A, Saha M, et al. A clinical study of pattern of skin manifestations in patients with systemic lupus erythematosus attending dermatology OPD in a tertiary care centre. J. Evolution Med. Dent. Sci. 2016;5(47):29842987, DOI: $10.14260 /$ jemds/2016/696

\section{INTRODUCTION}

Lupus Erythematosus (LE) is the root designation for a diverse array of illnesses that are linked together by the development of autoimmunity directed predominantly at the molecular constituents of nucleosomes and ribonucleoproteins. These manifestations encompass a spectrum ranging from a few localized discoid LE lesions to the life-threatening systemic manifestations such as nephritis, central nervous system disease or vasculitis of systemic LE. Thus, it is important to

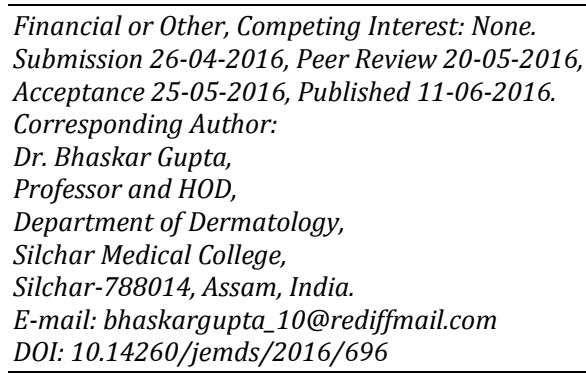

recognise the varied clinical manifestations at early part of disease and prevent or decrease the subsequent morbidity and mortality.

Skin is the second most common organ affected in Systemic Lupus Erythematosus (SLE). Cutaneous manifestations are often the first symptoms, which make the patient attend a dermatologist.

The diagnosis of cutaneous manifestations of SLE is based on clinical, histopathological and immunohistology of skin lesions. In addition, serum autoantibodies are considered as immunologic markers for distinct clinical types of the illness.

\section{Lupus Erythematosus (LE) is usually divided into Two} Main Types

Discoid LE (DLE) and Systemic LE (SLE) with a third group Sub-Acute Cutaneous LE (SCLE).

The nomenclature and classification system originally devised by James N. Gilliam divides the cutaneous manifestations of LE into those lesions that show 
characteristic histologic changes of LE (LE-specific skin disease) and those that are not histopathologically distinct for LE and/or may be seen as a feature of another disease process (LE-nonspecific skin disease). Within this context, the term, "LE-specific" relates to those lesions displaying an interface dermatitis. Moreover, lupus-specific skin lesions serve primarily as an important diagnostic clue, whereas lupus non-specific skin lesions are associated with more active disease and thus require more aggressive therapy and disease monitoring.

\section{MATERIALS AND METHODS}

This was a retrospective, observational study carried out in a tertiary care centre of North-East India over a period of 3 years (April 2013-March 2016).

38 patients of SLE ( 3 male and 35 female), attending the Dermatology OPD of a tertiary care centre were enrolled in the study after Institutional Ethical Clearance. Informed consent was obtained from all patients. Detailed history about symptoms, duration and evolution of cutaneous lesions was obtained. The patients were examined clinically focussing the mucocutaneous manifestations.

Routine and specific laboratory investigations were carried out to confirm the diagnosis of SLE under Revised American College of Rheumatology (ACR) criteria 1997.

\section{RESULTS}

\section{Cutaneous Manifestation of SLE}

\begin{tabular}{|c|c|c|c|c|}
\hline $\begin{array}{l}\text { Cutaneous } \\
\text { Lesion }\end{array}$ & Male & Female & Total & $\begin{array}{c}\text { Percentage } \\
(\%)\end{array}$ \\
\hline Oral ulcer & 2 & 24 & 26 & 68.42 \\
\hline Malar rash & 1 & 20 & 21 & 55.26 \\
\hline Photosensitivity & 2 & 19 & 21 & 55.26 \\
\hline Alopecia & 1 & 19 & 20 & 52.63 \\
\hline Discoid rash & 1 & 13 & 14 & 36.84 \\
\hline $\begin{array}{l}\text { Palpable } \\
\text { purpura }\end{array}$ & 0 & 10 & 10 & 26.31 \\
\hline Nail changes & 0 & 10 & 10 & 26.31 \\
\hline $\begin{array}{l}\text { Erythema } \\
\text { multiforme }\end{array}$ & 0 & 7 & 7 & 18.42 \\
\hline $\begin{array}{c}\text { Raynaud's } \\
\text { phenomenon }\end{array}$ & 0 & 5 & 5 & 13.15 \\
\hline SCLE lesion & 0 & 3 & 3 & 07.89 \\
\hline Bullous lesion & 0 & 3 & 3 & 07.89 \\
\hline Telangiectasia & 0 & 2 & 2 & 05.26 \\
\hline Facial oedema & 0 & 2 & 2 & 05.26 \\
\hline Panniculitis & 0 & 1 & 1 & 02.63 \\
\hline Cheilitis & 0 & 1 & 1 & 02.63 \\
\hline Lichen planus & 0 & 1 & 1 & 02.63 \\
\hline \multicolumn{5}{|c|}{ Table 1: Different Cutaneous Manifestation of SLE } \\
\hline
\end{tabular}

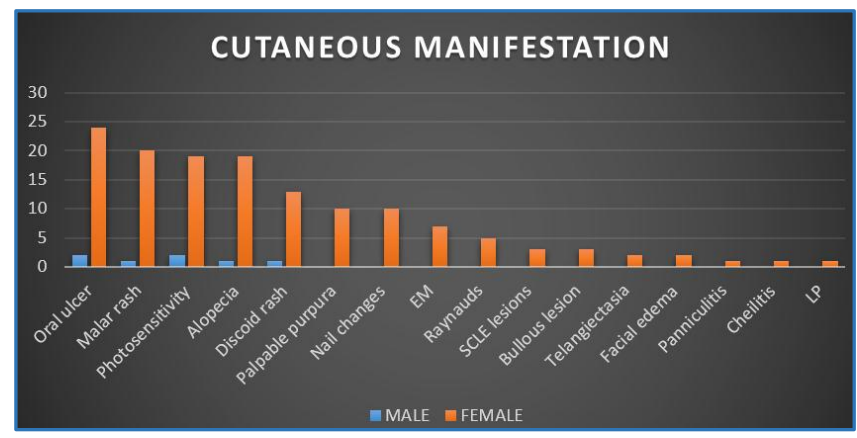

Graph 1: Cutaneous Manifestation of SLE

\begin{tabular}{|c|c|c|c|}
\hline Age Group & Male & Female & Total \\
\hline $0-10$ & 0 & 0 & 0 \\
\hline $11-20$ & 0 & 2 & 2 \\
\hline $21-30$ & 0 & 20 & 20 \\
\hline $31-40$ & 2 & 11 & 13 \\
\hline $41-50$ & 1 & 2 & 3 \\
\hline Table 2: Distribution of Patients According to the Age
\end{tabular}

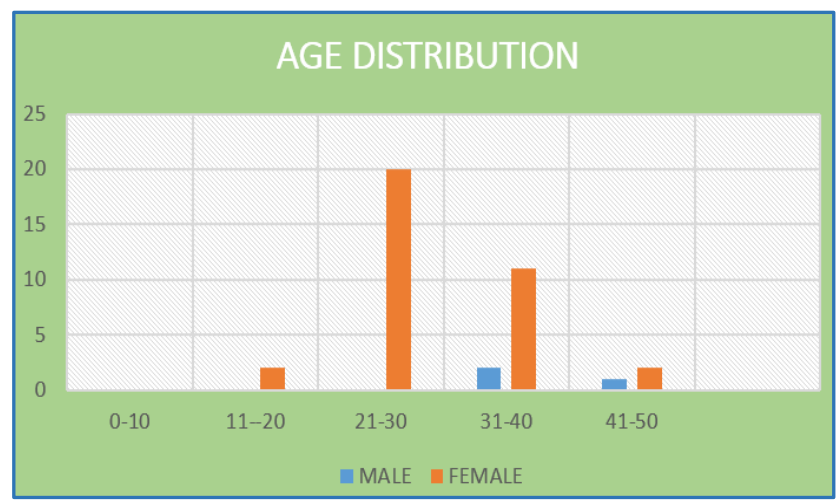

Graph 2: Distribution of Patients According to the Age

In our study, male-to-female ratio was $1: 11.5$ and maximum number of patients were seen in age group of 21-30 years with a median age of 26 years.

In our study oral ulcers were seen in $68.42 \%$, malar rash in $55.26 \%$, photosensitivity in $55.26 \%$, alopecia in $52.63 \%$, discoid rash in $36.84 \%$, palpable purpura in $26.31 \%$, nail changes in $26.31 \%$, erythema multiforme in $18.42 \%$, Raynaud's phenomenon in $13.15 \%$, subacute cutaneous LE in $07.89 \%$, bullous eruptions in $07.89 \%$, telangiectasia in $05.26 \%$, facial oedema in $05.26 \%$, lupus panniculitis in $02.63 \%$, cheilitis in $02.63 \%$, lichen planus in $02.63 \%$.

We did not see any case of pyoderma gangrenosum, livedo reticularis, chilblain lupus, Degos-like lesion/atrophie blanche, thrombophlebitis, episcleritis, rheumatoid nodules, erythromelalgia, sclerodactaly. Mucosa other than oral was not affected.

$26.31 \%$ patients presented with nail changes, and included paronychia (7.89\%), nail fold telangiectasia (5.26\%), onycholysis $(5.26 \%)$, ragged cuticles $(2.63 \%)$, leukonychia (2.63\%), splinter haemorrhages $(2.63 \%)$.

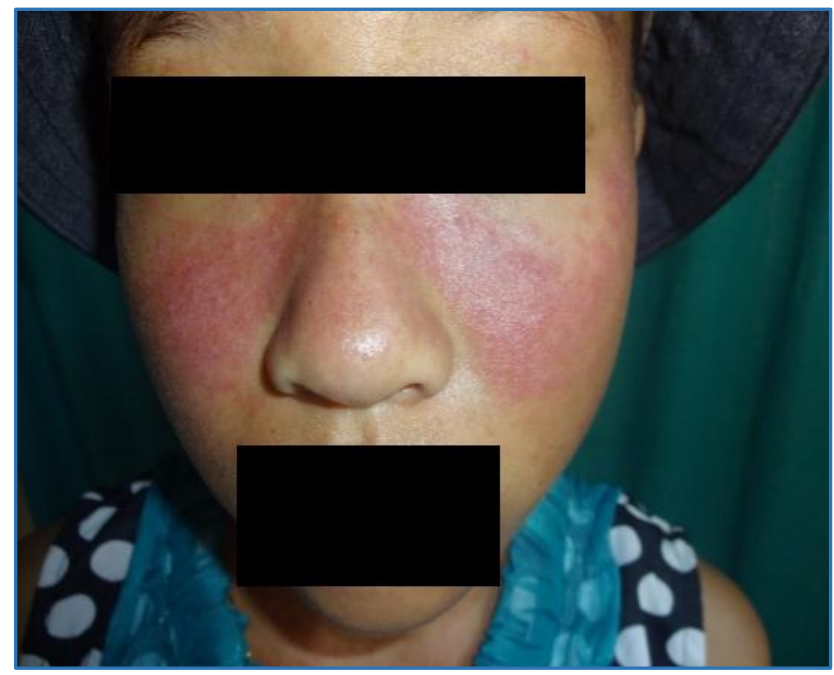

Fig. 1: A 14-Year Female Child with Typical Malar Rash 


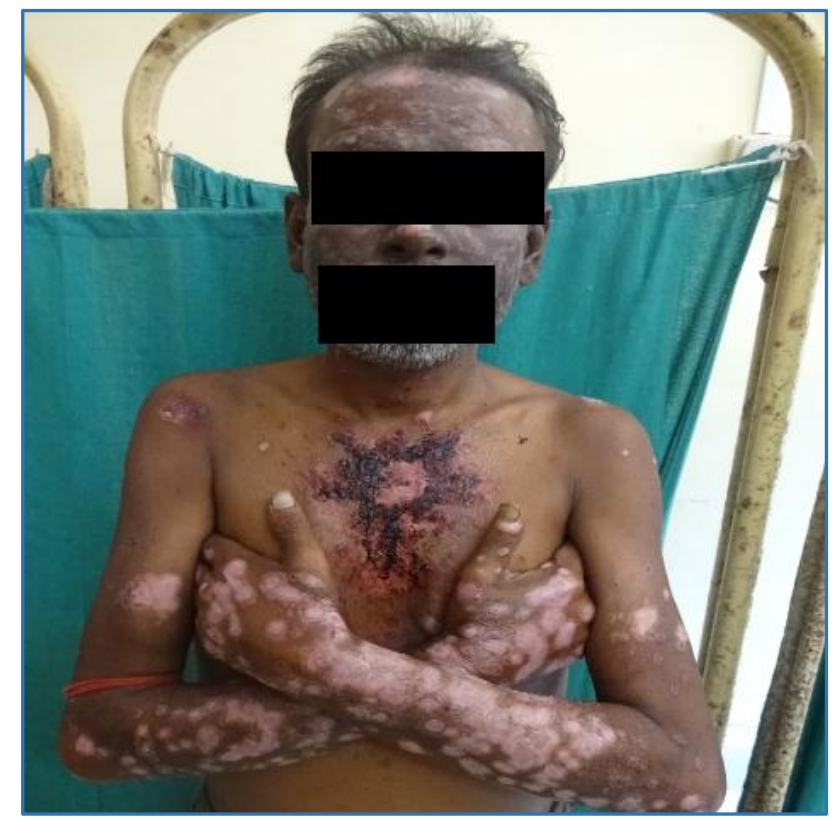

Fig. 2: A Male with Discoid Lesions and Lupus Hair

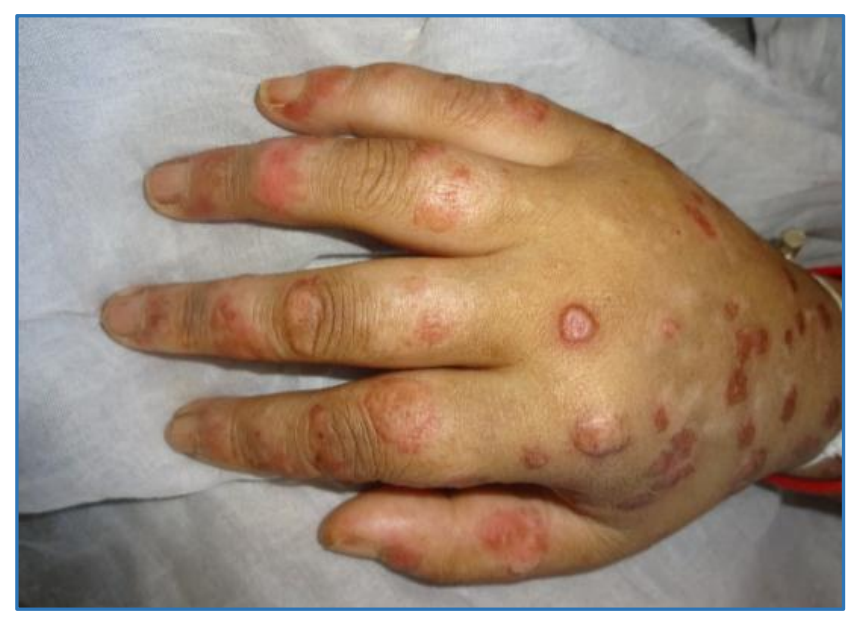

Fig. 3: Vasculitic Lesions

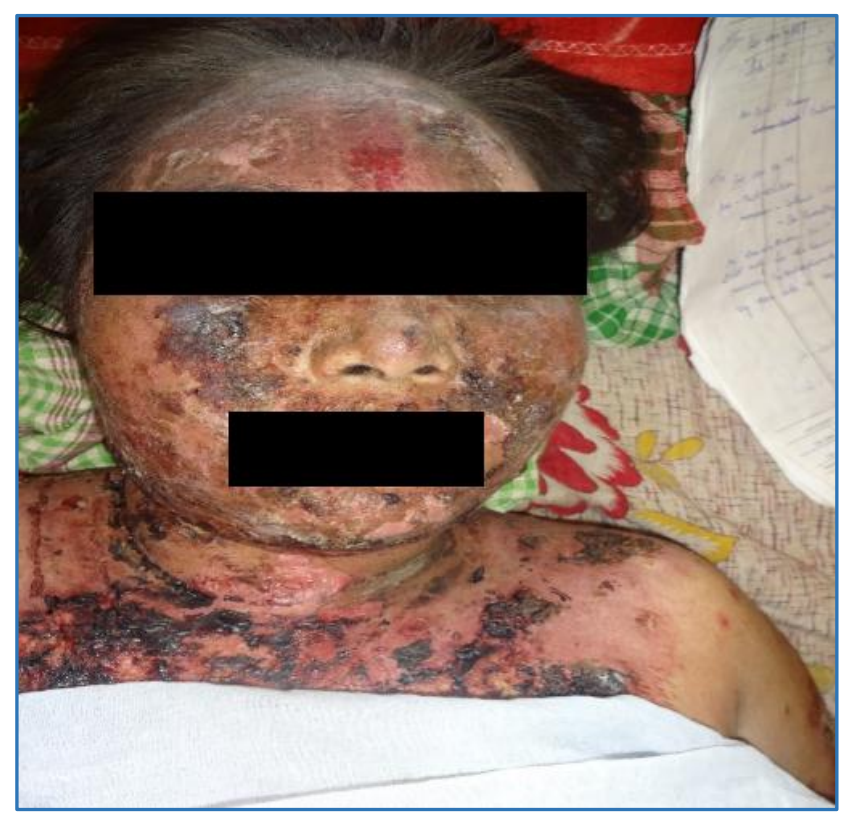

Fig. 4: Acute Cutaneous LE

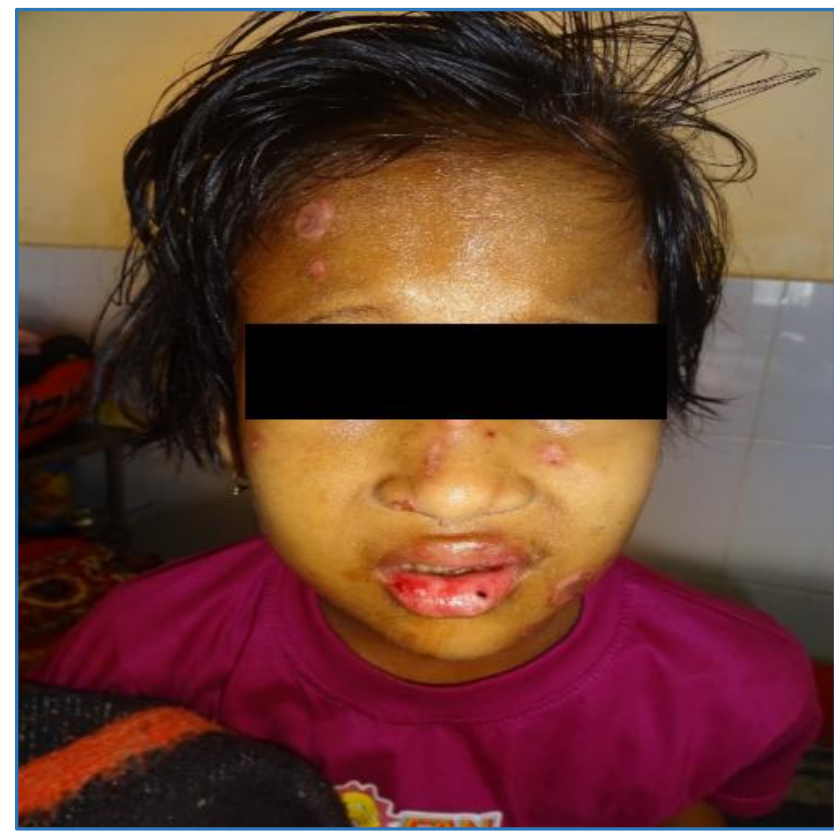

Fig. 5: A 13-Year Female Child with Oral Ulcers

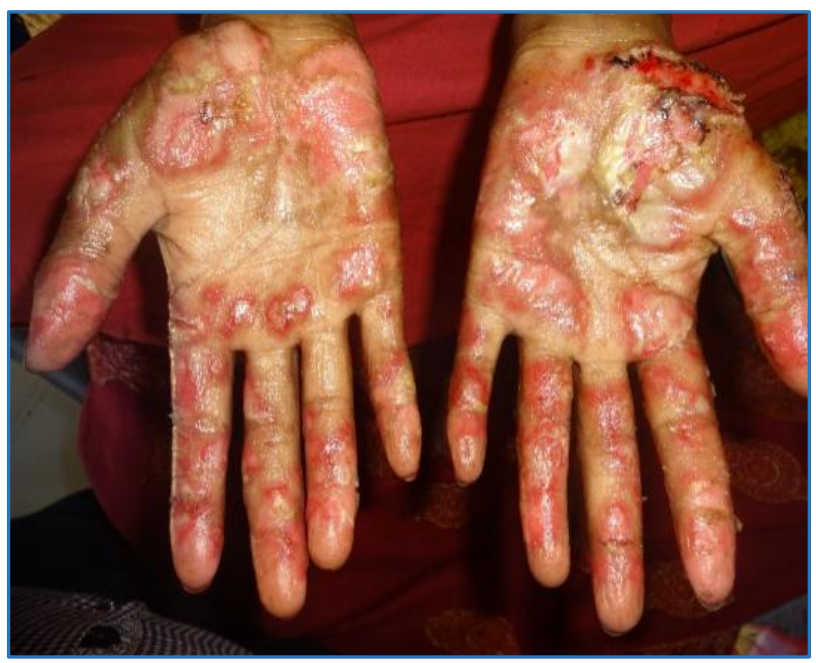

Fig. 6: Erythema Multiforme-Like Lesions

\section{DISCUSSION}

It was a retrospective, observational study where we enrolled patients based on modified American College of Rheumatology criteria.[1]

In current study, patients age ranged from 0-50 years with mean age of onset 26 years. Kole et al,[2] observed a mean age of disease onset as 25 years and male-to-female ratio as 1:14, Parveen et al ${ }^{[3]}$ observed mean age as 30.04 years and maleto-female ratio as 1:5; Masi et al[ ${ }^{[4]}$ observed a median age of disease onset as 31 years.

In our study oral ulcers were present in $68.42 \%$, while in study by Kole et al oral ulcers were present in $56.67 \%,{ }^{[2]}$ Parveen et al 34\%.[3] study by Patel et al 19\%.[5] Rabbani et al $21 \% .{ }^{[6]}$ Kapadia et al 60\%.[7] Yell JA et al 31.5\%.[8]

In our study, the frequency of malar rash was $55.26 \%$, while in study by Kole et al 80\%.[2], Parveen et al 70\%.[3], Patel et al 40\%.[5], Rabbani et al 31\%.[6], Kapadia et al 60\%.[7] Yell JA et al $51 \% .{ }^{[8]}$, Gronhagen $\mathrm{CM}$ et al $60 \% .{ }^{[9]}$

In our study the frequency of photosensitivity was $55.26 \%$, while in study by Kole et al $50 \% .{ }^{[2]}$, Parveen et al $75 \% .{ }^{[3]}$, 
Rabbani et al 33\%.[6], Kapadia et al 60\%.[7], Yell JA et al 63\%.[8] and Gronhagen CM et al 42\%.[9]

In our study the frequency of alopecia was $55.26 \%$, while in study by Kole et al $86.67 \% .{ }^{[2]}$, Parveen et al $47 \% .^{[3]}$, Patel et al 24\%.[5], Kapadia et al $82.5 \% .{ }^{[7]}$ and Yell JA et al $40 \% .{ }^{[8]}$

In our study the frequency of discoid rash was $36.84 \%$, while in study by Kole et al $20 \% .{ }^{[2]}$, Parveen et al $10 \% \cdot{ }^{[3]}$, Rabbani et al 15\%.[6], Kapadia et al 57.5\%.[7] and Yell JA et al $18 \%{ }^{[8]}$

\section{REFERENCES}

1. Tan EM, Cohen AS, Fries JF, et al. The 1982 revised criteria for the classification of systemic lupus erythematosus. Arthritis Rheum 1982;25(11):1271-7.

2. Kole AK, Ghosh A. Cutaneous manifestations of systemic lupus erythematosus in a tertiary referral centre. Indian J Dermatol 2009;54(2):132-6.

3. Parveen $N$, Das DK, Haque $M$, et al. Cutaneous manifestations of systemic lupus erythematosus. J Medicine 2007;8:44-8.
4. Masi AT, Kaslow RA. Sex effects in SLE: a clue to pathogenesis. Arthritis Rheum 1978;21(4):480-4.

5. Patel P, Werth V. Cutaneous lupus erythematosus: a review. Dermatol Clin 2002;20(3):373-85, v.

6. Rabbani MA, Ahmad A, Siddiqui BK, et al. Do clinical manifestations of systemic lupus erythematosus in Pakistan correlate with rest of Asia. J Pak Med Assoc 2006;56(5):222-7.

7. Kapadia N, Haroon TS. Cutaneous manifestations of systemic lupus erythematosus: study from Lahore, Pakistan. International Journal of Dermatology 1996;35(6):408-9.

8. Yell JA, Mbuagbaw J, Burge SM. Cutaneous manifestations of systemic lupus erythematosus. $\mathrm{Br} \mathrm{J}$ Dermatol 1996;135(3):355-62.

9. Grönhagen CM, Gunnarsson I, Svenungsson E, et al. Cutaneous manifestations and serological findings in 260 patients with systemic lupus erythematosus. Lupus 2010;19(10):1187-94. 